\title{
Ultrasound in the rural and remote healthcare setting
}

\author{
Pei Jun Zhao (Meds 2017) \\ Faculty Reviewer: Dr Rob Arntfield, MD, FRCPC (Division of Emergency Medicine)
}

\section{INTRODUCTION}

Sound plays an integral role in modern medicine. We can all picture the familiar image of a physician listening intently through a stethoscope to the lub-dub of the heart and the Korotkoff sounds of the brachial artery. But ultrasound imaging takes sound to a whole new frequency. Ultrasonography has even been described as the "stethoscope of the future". ${ }^{1}$ Through ultrasound, physicians are able to peer into the body to provide rapid bedside diagnosis of cholelithiasis, aortic aneurysm, hemoperitoneum, deep vein thrombosis, and much more. ${ }^{2}$ Moreover, ultrasound can be used to guide procedures such as fine needle aspiration biopsy and central line insertion. With advancement in technology, ultrasound machines are becoming less expensive and more compact, even reduced to the size of a hand-held device. ${ }^{2}$ Together, these factors allow ultrasound to be increasingly adopted by rural healthcare facilities.

\section{PRINCIPLES OF ULTRASOUND}

Ultrasound is defined as sound with frequency beyond the auditory range of the human ear-that is, $20 \mathrm{kHz}$ and higher. ${ }^{3}$ The frequency used in ultrasonography typically ranges from 2 to 12 $\mathrm{MHz}{ }^{3}$ Ultrasound with higher frequency and shorter wavelength has sharper resolution but shallower penetration. There are three common types of ultrasound transducers, also called probes. The convex and the phase array probes generate fan-shaped images while the linear probe provides a rectangular field of view. The phase-array probe, being smaller, can also image between obstructing structures such as ribs. ${ }^{4}$ Two very important dials on the ultrasound machine, other than the power button, regulate depth and gain. Depth controls how deeply or superficially the image is taken while gain adjusts the brightness of the display. ${ }^{4}$ Most ultrasound machines also have a Doppler mode that allows the quantification of movement, such as the velocity of blood flow through an artery. ${ }^{4}$ Lastly, air scatters ultrasound waves and creates fuzzy images, necessitating the liberal application of gel to minimize air interference between the skin and the probe.

\section{TRAUMA ULTRASOUND IN RURAL EMERGENCY MEDICINE}

In the rural healthcare setting, ultrasound can be used in many applications as a portable diagnostic tool to generate real-time images. It can be used to view arteries and veins, visceral organs such as the liver, gallbladder, kidneys, bladder, as well as the lung and the heart. ${ }^{2}$ In remote regions with little access to medical facilities, ultrasound may be useful in providing rapid and non-invasive diagnosis on site. Focused assessment with sonography for trauma (FAST) is one important application of ultrasound imaging. ${ }^{5}$ FAST is a bedside ultrasound protocol that examines the abdomen for hemoperitoneum and the heart for pericardial effusion. ${ }^{5}$ In the case of trauma patients, for whom prompt treatment is crucial to outcome, FAST enables rapid initial diagnosis such that immediate management decisions can be made.

Moreover, research is showing that FAST can be successfully used not only in the emergency department, but also on the field. Studies have demonstrated the efficacy of FAST during air medical transport, natural disaster rescue, as well as on the frontlines of the battlefield. ${ }^{6}$ Other conditions that can be assessed include high intra-cranial pressure, pneumothorax, high attitude pulmonary edema, and long bone fractures. ${ }^{6}$ Thus, emergency medicine ultrasound is a valuable tool for physicians practicing in rural areas with limited access to rapid diagnostic equipment typically taken for granted at larger, urban hospitals. In a survey of rural physicians, the importance of ultrasound resonated with the majority of respondents. ${ }^{7}$ Still, many physicians perceived a lack of immediate access to ultrasound equipment and felt that more training would be beneficial. ${ }^{7}$ While the value of ultrasound in rural environments is acknowledged, it is evident that there is significant room for growth.

\section{CARDIOVASCULAR SCREENING}

Ultrasound is useful not only for acute conditions such as trauma, but also for monitoring chronic illnesses such as cardiovascular disease. For seniors over the age of 65 , abdominal aortic aneurysms (AAA) affect 4 to $8 \%$ of men and $1.5 \%$ of women. ${ }^{8}$ In AAA, aortic weakening over years and decades leads to the formation of an aneurysm. Since rupturing of the aneurysm is associated with an 80 to $90 \%$ risk of mortality, AAA screening is recommended by the Canadian Society for Vascular Surgery. ${ }^{9}$

In rural populations at risk for AAA, the rate of screening has consistently been low due to the lack of hospitals and screening programs. ${ }^{9}$ Increased availability of ultrasound in rural clinics may increase the accessibility of AAA screening in these rural areas. In a recent study on the efficacy of ultrasound screening for AAA, rural family physicians in northern British Columbia trained in ultrasound imaging were able to safely screen a sample of 45 patients with no false positive or negative diagnoses. ${ }^{9}$ Other applications of ultrasound for the management of cardiovascular disease include the screening of deep vein thrombosis, echocardiography to assess heart function, and carotid ultrasound to evaluate stenosis.

\section{ULTRASOUND IN THE DEVELOPING WORLD}

In areas with insufficient healthcare infrastructure, ultrasound provides a relatively quick and inexpensive option for medical imaging. The added value of ultrasound has been verified by several studies conducted in a variety of centres with poorer access to healthcare, from rural district hospitals in Rwanda, to tertiary care centers in Liberia, to the jungles of the Amazon. ${ }^{10}$ In all of these cases, ultra- 
sound diagnosis was found to provide clinical insight that otherwise would not have been found through available examinations. Ultrasonography is able to generate clues, evaluate differentials, and narrow down on diagnoses. For example, in rural Mexico, hand-carried cardiac ultrasound was able to provide preliminary diagnoses for $90 \%$ of cardiac patients. ${ }^{11}$ In rural Zambia, imaging by focused maternal ultrasound prompted changes in clinical decision making for $17 \%$ of cases. ${ }^{12}$ The relative ease of operating ultrasound machines, the portability of the devices, and their broad applicability will allow ultrasound imaging to become an increasingly important tool for rural, underdeveloped parts of the world.

\section{TELESONOGRAPHY}

With advances in information sharing through the internet, "telesonography" has the potential to connect rural patients with quaternary medical centers in real-time. ${ }^{13}$ Ultrasound images generated at a relatively remote location-whether it is a community clinic, a farm, or even out in the wilderness-are transferred electronically to specialists who can provide an immediate diagnosis and medical advice. ${ }^{14}$ This can offset the disadvantage of not having specialist physicians in remote and sparsely populated areas. Thus, telesonography can greatly expand healthcare services provided in rural areas and save rural patients from multiple trips to the city to see the doctor. Recently, FAST has even combined with mobile telesonography such that ultrasound images taken during an ambulance trip can be transmitted live to the emergency physician. ${ }^{15}$ Training local healthcare providers in developing nations to operate ultrasound equipment can allow diagnoses to be made in consultation with medical colleagues at larger centers or even in another country. ${ }^{16}$ Thus, ultrasound has great potential in bringing care to underserved populations, thereby increasing healthcare accessibility.

\section{ULTRASOUND IN SPACE}

Finally, even in the most remote region of all-space-ultrasound has proven to be an effective tool for point-of-care diagnosis. In the International Space Station, under conditions of microgravity, astronauts trained in ultrasound were able to generate medical images and video of diagnostic quality that have been interpreted by physicians back on earth. ${ }^{17}$ Current applications of ultrasound in space include the monitoring of musculoskeletal health and the assessment of injuries due to trauma, and more applications are being studied and developed. ${ }^{18}$

\section{CONCLUSION}

Ultrasound imaging can and does play an important role in healthcare delivery in the rural and remote setting. The use of ultrasonography as a diagnostic tool at the point of care is gaining popularity, especially as ultrasound equipment becomes miniaturized and less expensive. Ultrasound is adaptable and versatile enough to serve a variety of clinical purposes, such as trauma assessment, cardiovascular screening, and astronaut health monitoring. With sufficient advances in technology and increased training opportunities, ultrasound imaging may soon evolve into an integral tool of all physicians' practices and become the stethoscope of this generation.

\section{REFERENCES}

1. Filly RA. Ultrasound: the stethoscope of the future, alas. Radiology 1988;167:400.

2. Minardi J, Davidov D, Denne N, Haggerty T, Kiefer C, Tillotson R, Whiteman C, Williams D, Williams D. Bedside ultrasound: advanced technology to improve rural healthcare. W V Med J. 2013;109:28-33.

3. Shipp TD. Basic principles and safety of diagnostic ultrasound in obstetrics and gynecology [Internet]. UpToDate. 2013 Jun 5 [cited 2013 Dec 1]. Available from: http://www.uptodate.com/ contents/basic-principles-and-safety-of-diagnostic-ultrasound-in-obstetrics-and-gynecology.

4. Ultrasound Fundamentals Tutorial [Internet]. Point of Care Ultrasound at Western University. 2013 [cited 2013 Dec 1]. Available from: http://westernsono.ca.

5. Ballantyne B et al. The current role of focused assessment with sonography for trauma (FAST) in the ever-evolving approach to abdominal trauma. UWOMJ 2012;81:20-2.

6. Nelson BP, Melnicker L, Li J. Portable ultrasound for remote environments, part II: current indications. J Emerg Med. 2011;40:313-21.

7. Flynn CJ, Weppler A, Theodoro D, Haney E, Milne WK. Emergency medicine ultrasonography in rural communities. Can $\mathrm{J}$ Rural Med. 2012;17:99-104.

8. Andreoli T et al. Andreoli and Carpenter's Cecil Essentials of Medicine. 8th ed. Philadelphia: Saunders Elsevier; 2010. 167 p.

9. Blois B. Office-based ultrasound screening for abdominal aortic aneurysm. Can Fam Physician. 2012;58:172-8.

10. Sippel S, Muruganandan K, Levine A, Shah S. Review article: Use of ultrasound in the developing world. Int J Emerg Med. 2011;4:72.

11. Kobal SL, Lee SS, Willner R, Aguilar Vargas FE, Luo H, Watanabe C, Neuman Y, Miyamoto T, Siegel RJ. Hand-carried cardiac ultrasound enhances healthcare delivery in developing countries. Am J Cardiol. 2004;94:539-41.

12. Kimberly HH, Murray A, Mennicke M, Liteplo A, Lew J, Bohan JS, Tyer-Viola L, Ahn R, Burke T, Noble VE. Focused maternal ultrasound by midwives in rural Zambia. Ultrasound Med Biol. 2010;36:1267-72.

13. Sutherland JE, Sutphin D, Redican K, Rawlins F. Telesonography: Foundations and Future Directions. JUM 2011;30:517-22.

14. Sheehan FH, Ricci MA, Murtagh C, Clark H, Bolson EL. Expert visual guidance of ultrasound for telemedicine. J Telemed Telecare. 2010;16:77-82.

15. Ogedegbe C, Morchel H, Hazelwood V, Chaplin WF, Feldman J. Development and Evaluation of a Novel, Real Time Mobile Telesonography System in Management of Patients With Abdominal Trauma. BMC Emerg Med. 2012;12:19.

16. Pian L, Gillman LM, McBeth PB, Xiao Z, Ball CG, Blaivas M, Hamilton DR, Kirkpatrick AW. Potential Use of Remote Telesonography as a Transformational Technology in Underresourced and/or Remote Settings. Emerg Med Int. 2013;2013:986160.

17. Kirkpatrick AW, Hamilton DR, Nicolaou S et al. Focused assessment with sonography for trauma in weightlessness: a feasibility study. J Am Coll Surg. 2003;196:833-44.

18. Sargsyan AE, Hamilton DR, Jones JA et al. FAST at MACH 20: clinical ultrasound aboard the international space station. J Trauma 2005;58:35-9. 